\title{
Investigation The Effect of Clearance and Body Weight on The Contact Pressure of Metal on PCU Hip Prosthesis using Finite Element Method
}

\author{
Wahyu Dwi Lestari ${ }^{1 *}$, Luluk Edahwati ${ }^{1}$, Wiliandi Saputro ${ }^{1}$, Ahmad $_{\text {Khairul Faizin }}{ }^{1}$, Radissa Dzaky Issafira $^{1}$, Nurmala \\ Shanti Dera ${ }^{2}$ \\ ${ }^{1}$ Department of Mechanical Engineering, Faculty of Engineering, University of Pembangunan Nasional Veteran Jawa Timur, 60294, \\ Indonesia \\ ${ }^{2}$ Department of Mechanical Engineering, Faculty of Engineering, Gorontalo University, 96211, Indonesia
}

\begin{abstract}
A common problem with artificial hip replacements is increased wear of the material in contact. Materials that are in contact result in contact pressure caused by the patient's daily activities so that it triggers wear. This study adopts a finite element method (FEM) to predict wear of the artificial hip joint, by studying the behavior of a hip joint prosthesis that has clearance under a certain load. The aim of this study was to observe contact as a function of clearance and body weight. The modeling uses metal as femoral head and polycarbonate urethane (PCU) material as the acetabular cup. Contact modeling as a hard material in contact with a deformable material. Four variations of clearance $(0.001,0.005,0.01,0.016)$ and three variations of body weight $(500 \mathrm{~N}, 700 \mathrm{~N}$, and $1000 \mathrm{~N})$ were used in this study. The simulation results show that the lower the distance and weight, the lower the contact pressure.
\end{abstract}

Keywords: FEM, Hip Prosthesis, Simulation

\section{Introduction}

Not a few people in this world who experience fractures in the hip joint due to accidents or calcification in the elderly, where one of the treatments is replacement with artificial hip joints. Many factors influence the success of a human hip replacement, including the surgical technique used, torso position and alignment, intramedullary fixation, implant design, body weight and others [1]. As medical practice shows, wear particles in the bearing are a major contributing factor in prolonging the life of the implant.[2]. In addition, joint function is also affected by the distribution of contact pressure in natural and artificial joints. As has been shown by several studies [3][4][5], the clearance between the two contact surfaces has an important role in the process of implant wear and friction.

Extending the life of the prosthesis to approximately 20 years to minimize revision surgery is a challenge for researchers today. Therefore, it is very important to continue research on wear for the development of new bearing pairs and design evaluation. One of the most common methods used by most researchers to observe wear on implant materials is to perform wear testing using a simulator in the laboratory [6]. However, conducting experimental studies in this way is quite costly and time consuming in its implementation, although it is very important to do a preclinical assessment of the wear parameters. Finally, wear modeling with a theoretical approach was carried out to reduce the number of experimental laboratory studies. This approach makes it possible to choose the material, design, observe the various variables that affect wear. Thus the resulting data can be used for further limited experimental testing. The basis of most of the approaches reported in the literature is the finite element method used for the definition of contact pressure on a contacting surface. The advantage of this method lies in its flexibility and can be used to study various designs, technologies and operations of prosthesis components [7].

The finite elemen method (FEM) has become the method of choice for analyzing the mechanical behavior of materials down to complex shapes and those subjected to complex loading. This is a mechanism that is widely used by researchers to study the contact between materials [8][9][10][11]. The extended finite element method (XFEM) was adopted by Bashiri et al [12] to predict the progressive failure of an artificially cemented hip joint. The results show that the initial location of the crack and the fracture path in the artificially cemented hip joint can be predicted using the XFEM. The finite elemen method was also used by Vogel et al [13] to observe the distribution of stress and

\footnotetext{
* Corresponding author: wahyu.dwi.tm@upnjatim.ac.id
} 
strain on the femoral neck and femoral head with different materials.

This study simulates the contact between the PCU material which will function as a bearing material and steel material as the femoral head. Recently, PCU material was introduced by several researchers as an alternative to UHMWPE for cushioning components in artificial joints in both hip and knee. Based on the observations made between the wear metal on PCU and the metal on the crosslink UHMWPE above several million loading cycles, it shows that there is a lower wear rate on the metal on PCU pair. In addition, it is known that PCU material can also increase protection against corrosion and wear particles that are less susceptible to osteolysis [14]-[17]. The aim of this paper is to analyze the effect of clearance and body weight on the contact pressure between the PCU on metal articulating surface. The analysis was carried out using the finite element method using the abaqus software. The data generated from the simulation process will be used to predict wear on the PCU material.

\section{Finite Element Model}

Biocompatibility is a key requirement in material selection for biomedical components such as hip joint replacements [18]. Material selection is done to minimize the presence of wear debris that causes damage to human body tissues in artificial hip joints [2]. The material must have corrosion resistant properties. Some metallic biomaterials that are often used for artificial implants are cobalt, magnesium, titanium based alloys, and stainless steel.[19]. In this study we use a pair of hard on soft materials, where hard materials use steel and soft materials use PCU.

The research using a finite element method (FEM) as the computational scheme. A parametric 2D axisymmetric FEM was done with the help of Abaqus software. The contact mechanics in two materials is treated as contact between rigid and deformable bodies. The finite element model consists of a perfectly rigid femoral head that articulates with the acetabular cup PCU. The contact mechanics modeling of the two materials is shown in Figure 1. The thickness of the acetabular liner is $15 \mathrm{~mm}$. The femoral head was constrained to fixed and the acetabular liner is pressed to the femoral head by acting along the acetabular cup/femoral head axis of symmetry. The femoral head is set to be at a clearance from the acetabular liner. In order to observe the effect of clearance on the artificial hip joint, several cases using variations of clearance and body weight. The elasticity modulus E and Poisson's ration $v$ were chosen as $20 \mathrm{MPa}$ and 0.5 respectively for the cup and $210000 \mathrm{MPa}$ and 0.29 respectively for the head. The mesh used by the acetabular cup is an axisymmetric solid element. The contact between the femoral head and the acetabular cup is modeled with classical isotropic Coulomb friction and implemented by the penalty method. In the simulation, surface-tosurface contact discretization is used. Rotational motion between the two components is neglected and only axial loads are considered.

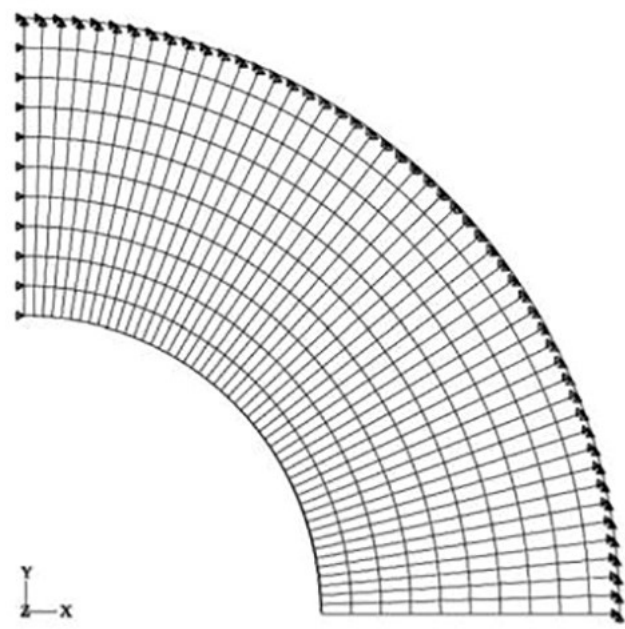

Fig. 1. Axisymetric model of femoral head and acetabular liner

\section{Result and Discussion}

Validation is carried out before carrying out the FEM simulation process. This is to minimize errors in performing the simulation step. The reference used to validate is research conducted by Tudor [5] as well as to compare the simulation results of this study. The results are shown in Figure 2. Validation was carried out for the acetabular cup thickness of $5 \mathrm{~mm}$. The contact pressure at the contact surface as a function of the contact radius obtained corresponds to that produced by Tudor. Based on the graph in Figure 2, it can be seen that the validation results are close to that of Tudor with an error percentage below $5 \%$. So it can be concluded that the simulation carried out is valid and can be continued for further research.

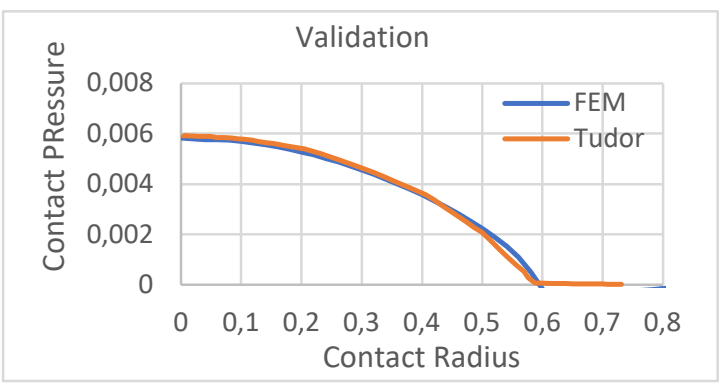

'Fig. 2. Validation of contact pressure simulation with Tudor research.

After the validation process has been carried out, the next step is to perform a simulation with the same steps but with different parameters. The parameters in this study are variations in clearance and body weight. There are 4 kinds of clearances that are simulated, namely $0.001,0.005,0.01$, and 0.016 . The body weight variations used are $500 \mathrm{~N}, 700 \mathrm{~N}$ and $1000 \mathrm{~N}$. This research variable was also adopted from a study conducted by Tudor and applied to this study with different materials. The simulation results of the contact 
pressure distribution with variations in clearance and body weight in this study are shown in Figure 3.

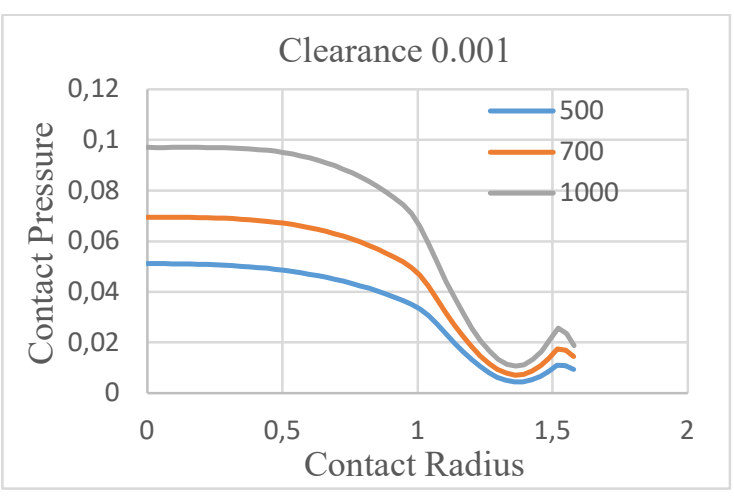

a

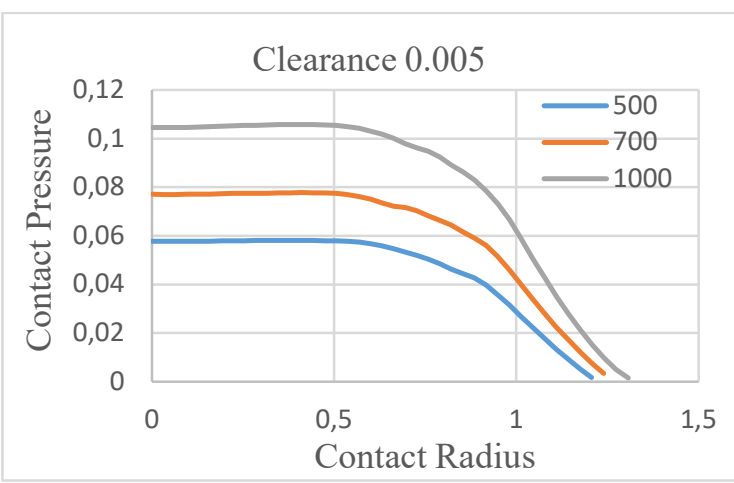

b
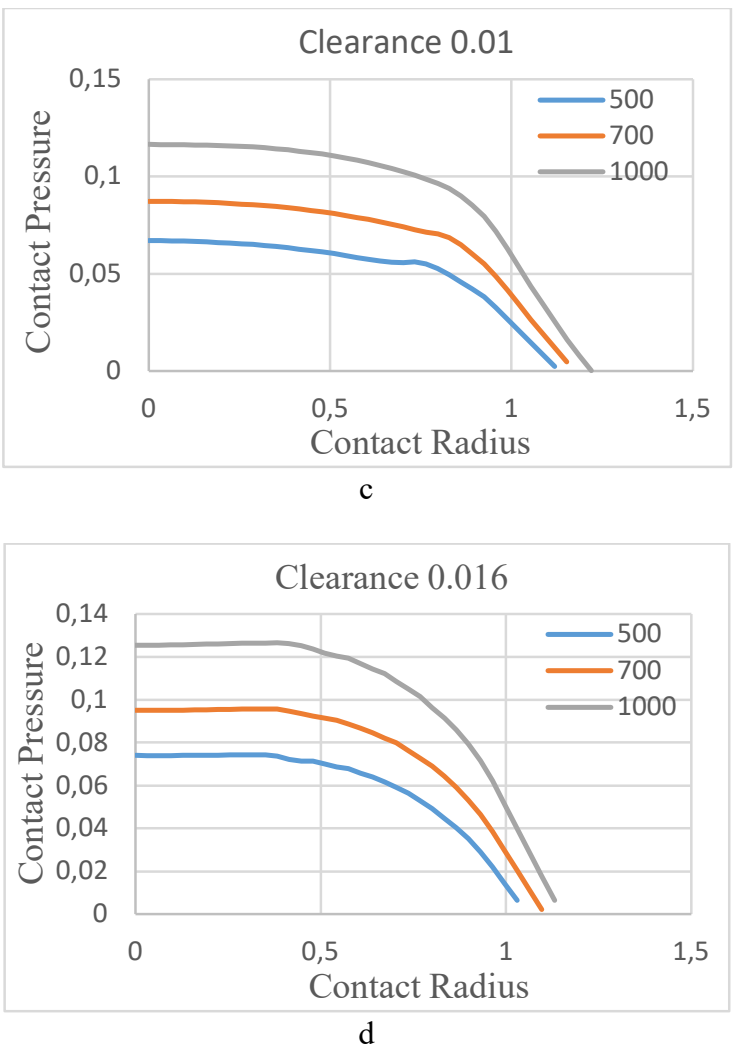

Fig. 3. Contact pressure distribution for different relative clearances and body weight.
The effect of clearance is very important in the wear of biomedical materials. This is because it can induce very high wear rates when it exceeds $2 \%$ or is close to zero. The ideal value is in the range of $1 \%$. This study underscores the importance of observing the bearing effect on PCU materials designed as a substitute for UHMWPE for bearings in artificial hip joints. The results in Figure 3 show that the contact pressure is small at a small clearance. The contact area and maximum contact pressure increase for high patient body weight. The high clearance causes a large contact pressure to be distributed over a small contact area, while the small clearance results in lower contact pressure distributed over a large area. Thus it can be said from the point of view of the maximum contact pressure, the smaller the clearance, the smaller the contact pressure, which means that the wear rate of the acetabular liner component will be smaller. This can be asked up to certain conditions. Maximum pressure alone can increase exponentially with decreased clearance due to pressure migration up the cup rim [8]. This indicates that in extreme conditions such as very small clearances or very large clearance can cause very high contact pressures.

\section{Conclusion}

Simulations contact mechanic of metal on PCU material for artificial hip joint implant were performed by FEM. The present work presents the numerical study which is useful for selection of PCU for artificial hip joint implants for better performance. From the simulation, it can be concluded that the lower the clearance and body weight, the lower the contact pressure value. The clearance in the artificial hip joint is very important from tribology because it will affect the level of wear. Through FEM it is possible to evaluate contact pressure, contact radius for each patient specific data such as weight, cup thickness, clearance and gait cycle. This computational model can be used for evaluation of implant design, surgery planning and patient recovery programs.

\section{References}

[1] J. Chao, Eng. Fail. Anal, 15, no. 1-2, pp. 83-89, (2008). doi: 10.1016/j.engfailanal.2006.11.017.

[2] E. Ingham and J. Fisher, Proc. Inst. Mech. Eng. Part H J. Eng. Med., 214, no. 1, pp. 21-37, (2000). doi: 10.1243/0954411001535219.

[3] L. Mattei, F. Di Puccio, B. Piccigallo, and E. Ciulli, Tribiology Int., 44, no. 5, pp. 532-549, (2011). doi: 10.1016/j.triboint.2010.06.010.

[4] Y. Yan, A. Neville, D. Dowson, S. Williams, and J. Fisher, Wear, 267, no. 5-8, pp. 683-688, (2009). doi: 10.1016/j.wear.2008.12.110.

[5] A. Tudor, T. Laurian, and V. M. Popescu, Tribol. Int., 63, pp. 158-168, (2013). doi: 10.1016/j.triboint.2012.11.002.

[6] J. G. Bowsher and J. C. Shelton, Wear, 250251, no. 1-12, pp. 167-179, (2001). doi: 
10.1016/S0043-1648(01)00619-6.

[7] J. S. S. Wu, J. P. Hung, C. S. Shu, and J. H. Chen, Comput. Methods Programs Biomed., 70, no. 1, pp. 81-91, (2003). doi: 10.1016/S01692607(01)00199-7.

[8] T. Laurian and A. Tudor, Ann. Univ. "“Dunarea Jos"' Galati, 1(1), pp. 393-7, (2003).

[9] S. H. Teoh, W. H. Chan, and R. Thampuran, J. Biomech., 35(3), pp. 323-330, (2002).

[10] W. D. Lestari, J. Jamari, and A. P. Bayuseno, AIP Conf. Proc., 020055, (2017). doi: 10.1063/1.4981196.

[11] W. D. Lestari, R. Ismail, J. Jamari, and A. P. Bayuseno, IOP Conf. Ser. Mater. Sci. Eng., 202 012098, (2017). doi: 10.1088/1757$899 X / 202 / 1 / 012098$.

[12] A. Bashiri, H. E. M. Sallam, and A. A. AbdElhady, Eng. Fail. Anal., 117, no. July, p. 104829, (2020). doi: 10.1016/j.engfailanal.2020.104829.

[13] D. Vogel, M. Wehmeyer, M. Kebbach, H. Heyer, and R. Bader, J. Mech. Behav. Biomed. Mater., 113, no. July 2020, p. 104115, (2021). doi: $10.1016 /$ j.jmbbm.2020.104115.

[14] R. A. Smith, A. Maghsoodpour, and N. J. Hallab, J. Biomed. Mater. Res. Part A, pp. 227234, (2009). doi: 10.1002/jbm.a.32531.

[15] S. M. Kurtz, R. Siskey, and M. Reitman, J. Biomed. Mater. Res. B Appl. Biomater., 93, n, pp. 442-447, (2010). doi: 10.1002/jbm.b.31601.

[16] J. J. Elsner, Y. Mezape, K. Hakshur, M. Shemesh, E. Linder-Ganz, A Shterling, N. Eliaz, Acta Biomater., 6, no. 12, pp. 4698-4707, (2010). doi: 10.1016/j.actbio.2010.07.011.

[17] M. Gupta, J. Biomater. Appl., 27(I), pp. 55-65, (2012). doi: 10.1177/0885328210394471.

[18] V. Jangid, A. K. Singh, and A. Mishra, Mater. Today Proc., 18, pp. 3867-3875, (2019). doi: 10.1016/j.matpr.2019.07.326.

[19] W. S. W. Harun, R. I. M. Asri, J. Alias, F. H. Zulkifli, K. Kadirgama, S. A. C. Ghani, J. H. M. Shariffuddin, Ceram. Int., 44, no. 2, pp. 12501268 , (2018).

doi: 10.1016/j.ceramint.2017.10.162. 